\title{
Sikap Orang Madura dalam Novel Ojung Karya Edi Ah Iyubenu
}

\author{
Muhammad Tauhed Supratman, Rahmad \\ FKIP, Universitas Madura Pamekasan \\ tauhed@unira.ac.id
}

\begin{abstract}
Characters and attitudes are often raised in a story or literary work involving the author himself to bring out what he has experienced, so that the reader can be clearly known by humanity's attitude as described in Ojung's novel. The novel, describes the attitude of Madurese people who are diverse in dealing with social problems such as brave attitude to bear the risks possessed by the main sitokoh, a very high attitude of confidence and confidence will come something he believes, egoism and ambition, willingness to sacrifice and virtuous tall one. Attitudes in a literary work can be diverse, including brave attitudes, high manners, selfishness, jealousy and envy of all and so on. The method used is a qualitative method. The results of the study illustrate the attitude of the Madurese people such as: the attitude of upholding self-esteem, courageous attitude to bear the risk.
\end{abstract}

Keywords: Life attitude, self-esteem, brave, Madurese, and ojung

\section{Intisari}

Karakter dan sikap sering dimunculkan dalam sebuah cerita atau karya sastra yang melibatkan si pengarang sendiri untuk memunculkan apa yang pernah dialaminya, sehingga dapat diketahui dengan jelas oleh pembaca sikap kemanusiaan yang sesungguhnya seperti yang digambarkan dalam novel Ojung ini. Novel tersebut, menggambarkan sikap masyarakat Madura yang beragam dalam menghadapi persoalan sosial seperti sikap pemberani menanggung resiko yang dimiliki oleh si tokoh utama, sikap yakin dan percaya diri yang sangat tinggi akan datangnya sesuatu yang dia yakini, sikap egoisme dan ambisi, sikap rela berkorban dan berbudi pekerti yang tinggi. Sikap dalam sebuah karya sastra bisa beragam yang dimunculkan, diantaranya sikap pemberani, budi pekerti yang tinggi, egois, iri dan dengki semua dan sebagainya. Metode yang digunakan adalah metode kualitatif. Hasil penelitian menggambarkan sikap hidup orang Madura seperti: sikap menjunjung tinggi harga diri, sikap pemberani menanggung resiko.

Kata kunci: Sikap hidup, harga diri, pemberani, orang Madura, dan Ojung.

\section{Pendahuluan}

Sastra adalah produk kebudayaan (karya seni) yang lahir di tengah-tengah masyarakat dan pengarang sebagai pencipta karya sastra, merupakan bagian dari masyarakat. Ide pengarang untuk menciptakan karya sastra berasal dari pembacaan subjektif pengarang (imajinasi) mengenai kondisi sosial masyarakat dari refleksi (objektif) pengarang atas kondisi sosial masyarakat yang ada sehingga melahirkan produk karya sastra yang memuat pembaharuan dalam nilai-nilai kehidupan dan kemasyarakatan. 
Novel sebagai sebuah karya fiksi sering mengisahkan sisi utuh atas problematika kehidupan seseorang atau beberapa orang tokoh. Novel adalah cerita berbentuk prosa dalam ukurannya yang luas. Ukuran yang luas disini dapat diartikan cerita dengan plot yang kompleks, karakter yang banyak, tema yang kompleks, suasana cerita yang beragam, dan setting cerita yang beragam pula (Sumardjo dan Saini , 1994:113)

Karakter dan sikap sering dimunculkan dalam sebuah cerita atau karya sastra yang melibatkan si pengarang sendiri untuk memunculkan apa yang pernah dialaminya, sehingga dapat diketahui dengan jelas oleh pembaca sikap kemanusiaan yang sesungguhnya seperti yang digambarkan dalam novel Ojung ini. Sikap dalam sebuah karya sastra bisa beragam yang dimunculkan, diantaranya sikap pemberani, budi pekerti yang tinggi, egois, iri dan dengki semua dan sebagainya.

Keunikan budaya Madura pada dasarnya banyak dibentuk dan dipengaruhi oleh kondisi geografis dan topografis hidraulis dan lahan pertanian tadah hujan yang cenderung tandus sehingga survivalitas kehidupan mereka lebih banyak melaut sebagai mata perncarian utamanya. Mereka pun dibentuk oleh kehidupan bahari yang penuh tantangan dan risiko sehingga memunculkan keberanian jiwa dan fisik yang tinggi, berjiwa keras dan ulet, penuh percaya diri, defensif dalam berbagai situasi bahaya dan genting, bersikap terbuka, lugas dalam bertutur, serta menjunjung martabat dan harga diri. Watak dasar bentukan iklim bahari demikian kadang kala diekspresikan secara berlebihan sehingga memunculkan konflik dan tindak kekerasan fisik. Oleh karena itu, perilaku penuh konflik disertai tindak kekerasan "dikukuhkan dan dilekatkan" sebagai keunikan budaya pada tiap individu kelompok atau sosok komunitas etnik Madura.

Penghormatan yang berlebihan atas martabat dan harga diri etniknya itu seringkali menjadi akar penyebab dari berbagai konflik dan kekerasan. Kondisi itu terjadi karena hampir setiap ketersinggungan senantiasa diklaim sebagai pelecehan atau penghinaan atas martabat dan harga diri mereka.

Kearifan budaya Madura yang juga menjadi keunikan etnografisnya tampak pada perilaku dalam memelihara jalinan poersaudaraan sejati. Hal itu tergambar dari ungkapan budaya oreng dhaddhi taretan, taretan dhaddhi oreng, (orang lain bisa menjadi/dianggap sebagai saudara sendiri, sedangkan saudara sendiri bisa menjadi/dianggap sebagai orang lain). Keunikan yang muncul dari ungkapan kultural (pseudo-kinship) itu diwujudkan dalam bentuk perilaku aktual. secara konkret, ucapan kultural tersebut memiliki makna 
bahwa kecocokan dalam menjalin persahabatan atau persaudaraan dapat dikukuhkan secara nyata dan abadi. Artinya, orang lain yang berperilaku sejalan dengan watak-dasar individu etnik Madura dapat dengan mudah diperlakukan sebagai saudara kandungnya (pseudo-kinship). Sebaliknya, saudara kandung dapat diperlakukan sebagai orang lain jika seringkali mengalami ketidakcocokan pendapat, pandangan, dan pendirian (Wiyata, 2005: 4; Astro, 2006: 2).

Keunikan "budaya persaudaraan” tersebut, menurut Glaser \& Moynihan (1981: 50) dapat terjadi karena adanya persamaan atau kesesuaian dengan keserupaan unsur-unsur penting primordial, misalnya genealogi (keturunan dan ikatan kekerabatan, sistem kepercayaan (agama dan ritulitasnya), dan kesamaan berbahasa. Realitas kehidupan masyarakat Madura menunjukkan bahwa elemen primordial itu dapat membentuk identitas etnik baru sebagai identitas tersendiri yang teraktualisasikan dalam perilaku etnografinya. Elemen primordial di antara kelompok-kelompok etnik tersebut dapat menjadi unsur pembeda.

Seringkali keunikan kultural melahirkan perilaku absurd berupa sikap defensif sebagian kelompok etnik Madura. Orang Madura dikenal mudah tersinggung harga-dirinya dan kemudian marah-marah, kemudian memilih alternatif solusi atas ketersinggungannya itu melalui kekerasan fisik, berupa carok.

Novel Ojung ini mengangkat persoalan kemanusian yang tercermin pada tokoh problematik yang sering bermasalah dengan kondisi sosial masyarakat. Edi AH Iyubenu menceritakan adanya masalah sosial yang dihadapi masyarakat ketika mereka menunggu datangnya hujan dalam waktu yang sangat lama, sehingga dalam novel tersebut dikisahkan tentang upacara memanggil hujan. Dalam kisah tersebut terjadi hal yang kontras, yakni dalam kehidupan yang serba modern mereka masih saja percaya terhadap tradisi atau upacara memanggil hujan yang di kenal dengan istilah Ojung. Sang tokoh utama Iyon sangat terobsesi mengadakan upacara tersebut karena hujan yang tak kunjung turun. Pada mulanya ia hanya pamer terhadap anak lelakinya yag kembar yang masih balita bahwa dia bias mendatangkan hujan, namun pada ahirnya sang tokoh tidak menyangka kalau ternyata upacara yang dia lakukan malah berahir dengan mengenaskan, yakni melukiskan kengerian dan bahaya implisit dunia gaib yang jauh dari ajaran agama. Novel tersebut, menggambarkan sikap dari masyarakat Madura yang beragam dalam menghadapi persoalan sosial seperti sikap pemberani menanggung resiko yang dimiliki oleh sitokoh 
utama, sikap yakin dan percaya diri yang sangat tinggi akan datangnya sesuatu yang dia yakini, sikap egoisme dan ambisi ,sikap rela berkorban dan berbudi pekerti yang tinggi.

\section{Metode Penelitian}

Penelitian ini merupakan penelitian sastra yang dirancang sebagai penelitian kualitatif dengan analisis deskriptif. Data penelitian ini berupa kata, kalimat dan paragraf yang relevan dengan fokus kajian (Miles dan Huberman, Ratna dalam Taufiq, 2017:5). Pendekatan yang digunakan adalah sosiologi sastra. Dipilihnya pendekatan sosiologi sastra didasarkan atas dua perspektif yaitu: (1) sastra merupakan sebuah cermin proses sosial ekonomi belaka, (2) mengutamakan teks sastra sebagai bahan penelitian (Damono dalam Endraswara, 2011:95). Sumber data penelitian ini adalah novel Ojung karya Edi AH Iyubenu. Data dalam penelitian ini adalah data kualitatif, yaitu data yang berupa kata-kata yang berkaitan dengan tradisi pernikahan dini dengan berbagai faktor yang mempengaruhi.

\section{Hasil dan Pembahasan}

\section{Sikap Menjunjung Tinggi Harga Diri}

Sikap masyarakat Madura yang berhubugan dengan sikap menjunjung tinggi harga diri difokuskan pada sikap budi pekerti dan pantang menyerah seperti yang terdapat dalam kutipan berikut :

" tapi aku merasa berdosa memakan gaji buta." “Ya, Lepaskan saja, toh kau tak lagi membutuhkannya toh."( Iyubenu,2013:40)

Kutipan di atas menggambarkan si tokoh aku memiliki sikap budi pekerti yang tinggi yakni menjunjung tinggi harga diri. Tokoh aku ciptaan Edi AH Iyubenu tidak menerima gaji dari pemerintah yang biasanya diterima setiap bulannya. Alasannya sangat sederhana karena dia sudah tidak bekerja lagi di kampus tersebut. Si tokoh aku juga sudah punya pekerjaan lain yang menghasilkan lebih banyak pemasukan dari sebelumnya, sehingga dia merasa makan gaji buta jika harus menerima gaji tersebut. Si tokoh aku pun ahirnya lebih memilih melepaskan pekerjaan sebelumnya. Pernyataan tersebut juga dipertegas lagi pada kutipan berikut ini :

"Usulnya saya kira sangat masuk akal. Harus diakui bahwa pemasukan dari taтu-tamu yang berdatangan itu jauh lebih memuaskan daripada gaji yang saya terima setiap awal bulan.Tak ada seperempatnya! Saya katakan pada istri saya, " aku mau mengundurkan diri dari kampus." (Iyubenu,2013:40) 
Berikut ini juga dapat dilihat gambaran tentang sikap budi pekerti yang di perankan si tokoh aku dalam novel Ojung tersebut, yaitu :

Terimakasih, bang”

"sama-sama "(Iyubenu,2013:52)

Ungkapan "terima kasih" ini sudah sangat jelas melambangkan sikap budi pekerti yang tinggi dari tokoh aku, setiap kali menerima bantuan atau sesuatu dari orang lain. Senada dengan kutipan di atas, percakapan berikut ini juga merupakan gambaran dari sikap menjunjung tinggi harga diri yaitu :

"Bagaimana belanjaanmu?”.

“Sudahlah, lupakan, lain waktu pun bisa” (Iyubenu,2013:76)

Anjuran dari tokoh aku kepada si istri untuk melupakan hal-hal yang kurang berkenan tersebut menandakan sikap budi pekerti menjunjung tinggi harga diri dan rasa peduli akan kondisi si istri, sehingga si istri tidak menanggung beban hidup sendirian. Demikian halnya dengan kutipan berikut.

"Sentuhlah tanganku, sebentar lagi kita berpisah"

"Tidakkah kau lihat betapa kami sangat membutuhkannya? Tidakkah kau bayangkan betapa ringkihnya hidup kami tanpa tawa candanya? Pikirkan itu Izrail, rasakan dengan batinmu” (Iyubenu, 2013:107)

Dalam kutipan tersebut si tokoh Sarinem mengungkapkan kalimat tersebut pada sang kakek yang hendak berpisah dengannya. Pada kutipan berikutnya tokoh sarinem menyesalkan sikap anaknya ( Israil ) yang telah membuat perasaan si kakek ayah Sarinem tersinggung dengan kata- kata anaknya.

Tidak hanya gambaran tentang sikap dan budi pekerti dalam kriteria sikap menjunjung tinggi harga diri, akan tetapi kutipan - kutipan berikut ini mencerminkan sikap pantang menyerah yaitu :

"Kalo bapak mau bersabar, saya punya teman pemusik yang hobi mengoleksi berbagai jenis music daerah .Barang kali dia menyimpan rekaan music minta hujan itu "(Iyubenu,2013:130)

Si tokoh pak Daman membujuk sopirnya untuk membantunya mencarikan sarat - sarat untuk pelaksanaan upacara Ojung yaitu musik daerah. Demi menjunjung tinggi harga diri dia rela berkorban untuk bersusah payah mencari syarat - syarat tersebut tanpa merasa putus asa.

Kutipan berikut ini juga mencerminkan tentang sikap pantang menyerah yang diperankan oleh para tokoh dalam novel Ojung : 
Semalam,kau apakan anak-anak ? Mau mendatangkan hujan ? mau menjadi dukun? (Iyubenu,2013:67)

Walaupun istri dari pak Daman marah karena perlakuannya terhadap kedua anak kembarnya yang dijadikan sarat dalam upacara Ojung tersebut, Pak Daman tidak menghiraukan kata- kata istrinya demi keinginannya untuk mendatangkan hujan dia tetap kokoh pada pendiriannya menjadikan kedua anak kembar nya sebagai sarat untuk di adu dalam upacara Ojung tersebut.

"kakek harus jaga kesehatan minum obat dan banyak istirhat agar sembuh(Iyubenu,2013:155)

Kutipan tersebut melambangkan akan kecintaan sang anak pada sang ayah, walaupun dia tau kalo ayahnya sedang menderita penyakit kronis yang tidak kunjung sembuh, namun dia pantang menyerah, selalu mendukung sang ayah agar tetap semangat dalam menjalani hidup ini.

\section{Sikap Pemberani Menanggung Resiko}

Sikap hidup masyarakat Madura yang kedua adalah sikap pemberani menanggung resiko, berwatak keras, dan sikap antusias serta percaya diri yang diantaranya dapat dilihat pada kutipan berikut ini :

" Jadi,dia nggak ngasih uang ?” " Tidak,hanya batu kecil hitam ini."(Iyubenu,2013: 64)

Kutipan tersebut termasuk sikap pemberani dan berwatak keras, tanpa rasa takut istri dari pak Daman mengeluhkan pada suaminya karena tamunya tidak membawa uang hanya sebuah batu hitam kecil. Baginya setiap tamu yang datang ke rumahnya harus membawa uang bukan sekedar batu hitam itu. Pak Daman tidak mengikuti kemauan isterinya, dia tetap menyimpan batu hitam itu sambil menunjukkan kapada kakaknya, ternyata batu hitam kecil itu bukanlah sedar batu biasa, tetapi merupakan pertanda bahwa lambat laun dia akan menjadi dukun besar dan terkenal yang akan membawa perubahan menurut ramalan kakak kandungnya. Kutipan berikut ini juga merupakan sikap pemberani yaitu :

Ayo,buang lidi itu! (Iyubenu,2013: 64) 
Isteri pak Daman meminta anaknya untuk membuang lidi yang sedang di pegang oleh kedua anak kembarnya yang sedang bertarung dalam rangka upacara Ojung dia tidak suka suaminya mengadakan upacara tersebut, apalagi sampai melibatkan kedua anak kembarnya untuk bertarung saling pukul. Istri Pak Daman meminta anaknya untuk membuang lidi itu, walaupun harus merusak upacara yang diadakan suaminya.

Sedangkan sikap pemberani menanggung resiko yang terdapat unsur antusias dan percaya diri terdapat dalam kutipan berikut ini:

"Tapi kata bik inem, hujan tak akan turun lagi disini,pak?"

" bapak bisa mendatangkannya kok?"

(Iyubenu,2013: 64)

Kutipan tersebut merupakan ungkapan dari anak kembar pak Daman yang di adu dan disuruh bergulat sebagai salah satu sarat dalam upacara Ojung kepada bapaknya (si tokoh yang sangat antusias mengadakan upacara Ojung), menanyakan soal hujannya yang belum turun, namun pak Daman tetap yakin kalau dengan upacara Ojung tersebut dia bisa mendatangkan hujan.

“Pak,hujannya kok belum turun juga ?(Iyubenu,2013:65)

Sarinem memberanikan diri menanyakan soal hujan yang tidak kunjung turun kepada majikannya, pak Daman, padahal sudah mengadakan upacara Ojung. Kutipan berikut ini merupakan sikap pemberani menanggung resiko yaitu :

Oii, hati-hati main sama bule, banyak penyakitnya, lebih baik sama kitalah! (Iyubenu,2013:52)

Tanpa rasa takut Israil melontarkan kata-kata tersebut sambil diguyonkan pada temannya yang sedang berjalan dengan bule, dia kuwatir takut temannya hanya di jadikan sebagai mainan seperti pada umumnya, makanya dia bilang kalau bule banyak penyakitnya dengan maksud agar teman perempuannya tersebut tidak jadi pergi dengan bule, dia tidak memikirkan resiko dari kata- kata yang diucapkannya itu, tidak peduli apakah si bule marah atau tidak, yang penting baginya temannya menghindari bule itu, karena dia memiliki pandangan yang negatif terhadap bule tersebut. Berikut ini juga merupakan kutipan tentang sikap pemberani menanggung resiko yaitu :

“ini salahku, emmak begini karena kecewa padaku” (Iyubenu,2013:76) 
Sarinem menyalahkan dirinya karena ibunya yang pergi meninggalkan keluarga besarnya.

Para bedebah! Kalian telah menghancurkan perjumpaanku dengan perempuan itu! Kalian sungguh kurang ajar! Bangsat.....!!!"

"Kalian telah menghancurkanku!"

"Kakek, tenang, tenang" (Iyubenu,2013:159)

Sikap masyarakat Madura yag di perankan oleh tokoh- tokoh tersebut melambangkan sikap pemberani dan berwatak keras. Dalam kutipan diatas, ayah sarinem marah pada keluarga besarnya, tanpa rasa takut dia menyesalkan sikap anak dan cucunya. Dia berani mangatakan anak cucunya para bedebah karena telah membuat tersinggung isterinya dan pergi maninggalkan dirinya dan keluarga besarnya.

\section{Simpulan}

Berdsarkan hasil deskripsi data diatas, dapat disimpulkan bahwa sikap masyarakat Madura dalam novel Ojung karya Edi AH Iyubenu dapat disimpulkan sebagai berikut :

Sikap menjunjung tiggi harga diri ( MTHD ) yang meliputi sikap berbudi pekerti dan pantang menyerah dalam novel Ojung yang di perankan oleh para tokoh Madura seperti Pak Pri, Bik inem, Maman, Daman dan si Bapak, dapat dilihat ketika mereka bersikeras mengadakan upacara Ojung dalam rangka untuk mengharapkan hujan turun. Sikap budi pekerti ditunjukkan oleh bik Inem dan pak Pri serta sikap pantang menyerah diperankan Maman dalam upacara tersebut, ketika hujannya tidak kunjung turun.

Sikap pemberani menanggung resiko ( PMR ) yang terdiri dari sikap pemberani dan berwatak keras juga diperankan oleh tokoh Daman dan Maman serta si Bapak ketika bertarung adu pukul sebagai syarat dalam upacara Ojung untuk mendatangkan hujan.

\section{Daftar Pustaka}

Astro, Masuki M. 2006. Orang Madura peramah yang Sering Dikonotasikan Negatif. (http://www.mamboteam.com) diakses 4 November 2013.

Adi, Ida Rochani. 2011. Fiksi Populer: Teori dan Metode Kajian, Yogyakarta: Pustaka Pelajar

Endraswara, Suwardi. 2011. Metodelogi Penelitian Sosiologi Sastra. Yogyakarta: CAPS.

Faruk, 2012. Pengantar Sosiologi Sastra, Yogyakarta: Pustaka Pelajar

Iyubenu, Edi AH 2003.Ojung.Yogyakarta:Pustaka Sastra.LKIS 
Nugiyantoro, Burhan. 2010.Teori Pengkajian Fiksi, Yogyakarta: Gadjah Mada University Press

Pradopo, Rachmat Djoko.2010. Pengkajian Puisi, Yogyakarta: Gadjah Mada University Press

Rifai, Mien Ahmad. 2007. Manusia Madura.Yogjakarta : Nuansa Aksara.

Taufiq, Akhmad. 2017. Sastra Multikultural: Konstruksi Identitas dan Praktik Diskursif Negara dalam Perkembangan Sastra Indonesia. Malang: Beranda

Wiyata, A. Latief. 2013. Mencari Madura. Jakarta: Bidik-phronesis publishing.

Wiyata, A. Latief. 2003. Madura yang Patuh?; Kajian Antropologi Mengenai Budaya Madura. Jakarta: CERIC-FISIP UI. 